\title{
Análisis de un caso de propaganda bélica antijaponesa
}

Jesús Jiménez-Varea | jjvarea@us.es

UNIVERSIDAD DE SEVILLA

Resumen: En este artículo se comprueba cómo el modelo estructural del mensaje propagandístico propuesto por Pineda Cachero permite analizar la portada del comic book The Human Torch Comics no 12 como un caso particular de propaganda bélica en el curso de la II Guerra Mundial.

Palabras clave: propaganda, comic books, superhéroes, II Guerra Mundial

Abstract: This paper demonstrates how the structural model of the propagandistic message advanced by Pineda-Cachero permits to analyze the cover of the comic book The Human Torch Comics num. 12 as a particular case of war propaganda in the course of World War II

Key words: propaganda, comic books, superheroes, II World War 


\section{Modelo de análisis}

De acuerdo con el modelo estructuralista del mensaje propagandístico propuesto por Pineda (2006: 235-345), éste se materializa por fijación de variables de su estructura superficial, los elementos estético-expresivos (EEE): "el lenguaje [...] la imagen [...], el sonido y la música, etc. [...] Los personajes concretos, los textos y sus recursos, las propiedades tecnológicas del medio utilizado, etc." (ibídem: 310). Los EEE constituyen la fachada significante del mensaje propagandístico, cuyo significado tiene como unidad mínima un propagandema (PMA): "algún tipo de unidad o elemento semántico que vincule la ideología con lo auténticamente importante: los intereses de poder del Emisor" (ibídem: 252-253). A su vez, esa intención de poder del emisor se inscribe en este esquema formal bajo la denominación de propagado (PDO): "lo que recibirá los beneficios del control del pensamiento del Receptor ejecutado por la propaganda" (ibídem: 242). Clave en esta modelización de la comunicación propagandística es la conexión PDO-PMA: "el modo en que las condiciones de emisión de la propaganda generan un mensaje con el fin de alcanzar sus objetivos y cumplir la lógica de dichas condiciones" (ibídem: 263). Según el grado de "correspondencia entre los intereses y objetivos reales del poder (PDO) y la representación propagandística de los mismos (PMA)" (ibídem: 267), no hallaremos ante un enmascaramiento mayor o menor tras una ideología de las intenciones reales del emisor a ojos del receptor. El peso de esta instancia receptora en la comunicación propagandística se halla empequeñecido por el del emisor, pues toda ella se subordina al explicans del fenómeno, una relación de poder $(P)$ del emisor sobre el receptor: "una intención comunicativa propagandística dirigida a controlar el pensamiento de un receptor" (ibídem: 238). La presencia del receptor en el mensaje queda reducida al estatus no universal de una serie de condiciones de recepción (CR), "predisposiciones actitudinales" y "elementos de contenido" (ibídem: 279), ya sean culturales (CR-C) o universales (CR-U), que el emisor puede imputarle y usar en la formulación de la conexión PDO-PMA, así como en su posterior plasmación mediante unos ciertos EEE. Todos los elementos del modelo, excepto su principio animador $(\mathrm{P})$, están sometidos a una polarización semiótica como consecuencia de la "lógica dicotómica-antitética (+/-) de la propaganda [...] una oposición tajante entre lo que se incluye en el campo de [los intereses del emisor] y lo que se opone a ellos" (ibídem: 241). En conjunto, Pineda organiza los componentes y relaciones de este modelo estructural de la propaganda en una representación arborescente (véase la figura siguiente, tomada de ibídem: 319 ) que comprende tres modalidades posibles (ibídem: 245):

- Afirmación $\left(\mathrm{P}_{\mathrm{a}}\right)$ : PDO $(+)$

- Reacción $\left(\mathrm{P}_{\mathrm{r}}\right)$ : PDO $(-) \rightarrow$ PDO $(+)$

- Negación $\left(P_{n}\right)$ : PDO $(-)$ [PDO $\left.(+)\right]$. 


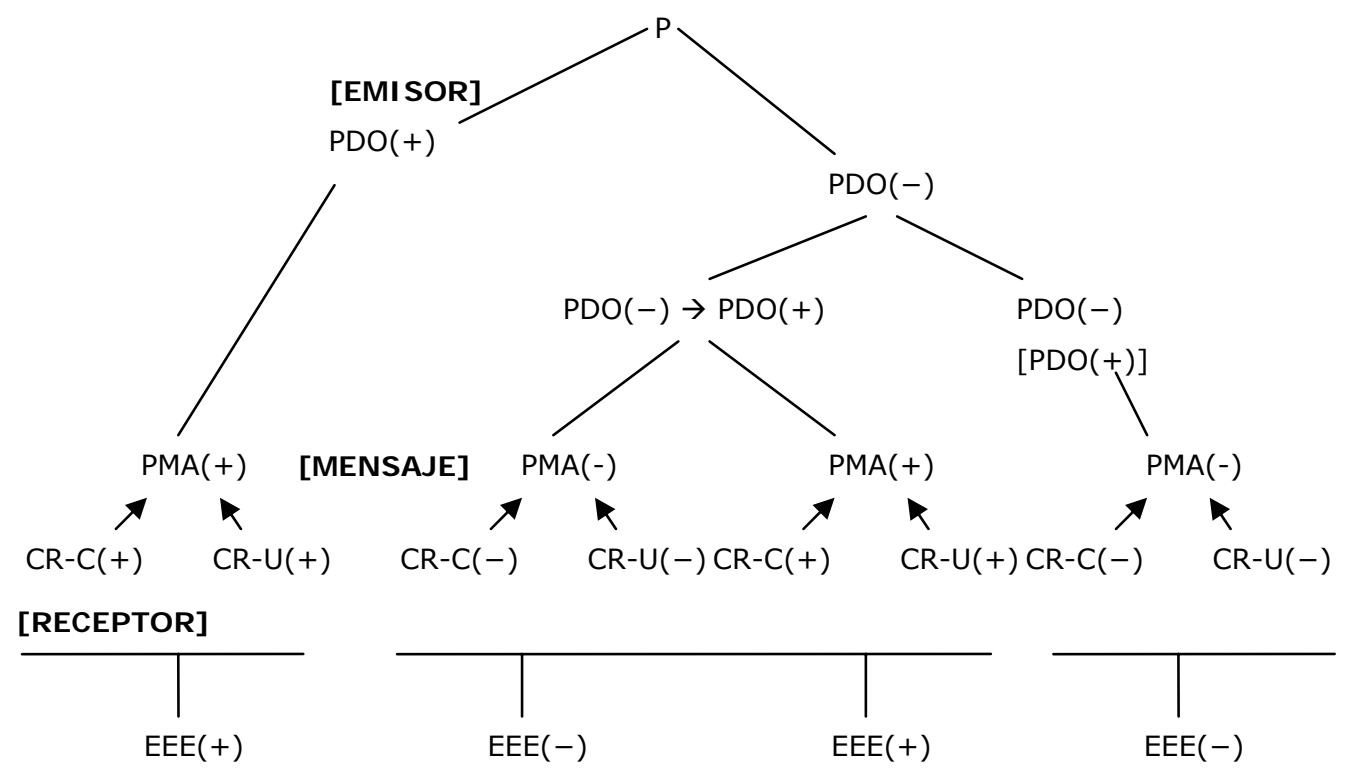

[MENSA] E + MEDI O]

Al avanzar un propagandema, el analista que aplica este modelo parte del terreno de la conjetura, a la espera de su confirmación por la vía de una hipotética convergencia sémica basada en la observación de los EEE (ibídem, 2006: 257). Esta idea remite de inmediato a la noción de isotopía definida por Greimas: "el conjunto redundante de categorías semánticas que hace posible la lectura uniforme del relato" (1973: 222). A Greimas y Courtés se debe el método para la lectura isotópica de los textos narrativos, que no se limitan a la expresión lingüística y en cuya organización semántica distinguen tres niveles:

- Figurativo: "[...] en un universo de discurso dado (verbal o no verbal) [...] todo lo que depende de la percepción del mundo exterior" (Courtés, 1997: 238).

- Temático: "Si lo figurativo se define por la percepción, lo temático se caracteriza por su aspecto propiamente conceptual. [...] son conceptos abstractos"; sí son perceptibles sus representaciones en el discurso, "que por otra parte son variables según los universos socioculturales" (ibídem).

- Axiológico: resulta de la asignación de los valores bueno (euforia) o malo (disforia) a las categorías temáticas (ibídem: 252-253). Es evidente la semejanza entre este nivel y la polarización semiótica a través del binomio $(+) /(-)$ en el modelo de propaganda de Pineda.

Se trata de una segregación en distintos niveles de significación, como también se encuentra en el clásico "Rhétorique de l'image" de Barthes. Pineda señala la analogía entre las relaciones denotación-connotación y EEE-PMA: Ios primeros (denotación, EEE) restringen el 
potencial interpretativo de los textos y permiten determinar los segundos (connotación, PMA). Pese a la "'chaîne flottante' de signifiés", la lectura de una imagen se verifica debidamente gracias a posibles mensajes lingüísticos de anclaje (Barthes, 1964: 44), así como a las operaciones retóricas en el texto visual. Retomando la línea de Barthes, Durand afirmó: "[...] la rhetorique met en jeu des niveaux de langage (le 'langage propre' et le 'langage figuré'), et [...] la figure est una opération qui fait passer d'un niveau de langage à l'autre" (1970: 70). Posteriormente, el Groupe $\mu$ la definió también en función de dos niveles: "la retórica es la transformación reglada de los elementos de un enunciado, de tal manera que en el grado percibido de un elemento manifestado en el enunciado, el receptor deba superponer dialécticamente un grado concebido" (1993: 231-232). Estas aproximaciones fundamentan la coherencia teórica y la pertinencia metodológica de considerar dos niveles, uno denotativo y otro connotativo, a la hora de analizar los EEE de un mensaje propagandístico.

Aunque alejado de la corriente estructuralista ${ }^{1}$, el protocolo de investigación del objeto artístico de Panofsky tiene en común con los anteriores la implicación de un proceso netamente connotativo, donde el significado referencial actúa como significante de otro nivel de significado que exige interpretación. Panofsky (1987: 47-50) distinguió tres niveles de significación en el arte figurativo:

- Significación natural, que puede ser fáctica (reconocimiento de los objetos y actos gracias a la experiencia) o expresiva (aprehensión de matices psicológicos de los personajes); nivel de la descripción pre-iconográfica.

- Significación convencional, resultante de la aplicación de los códigos de un entorno cultural compartido (temas, historias, alegorías); nivel del análisis iconográfico.

- Significación intrínseca, consistente en fragmentos de información sobre expectativas, inclinaciones e intereses de una tradición, una comunidad o un autor; nivel de la interpretación iconológica.

Los dos primeros niveles pertenecen al propio objeto artístico, funcionando efectivamente como una forma de connotación. Trasladado al modelo de Pineda, el análisis iconográfico asiste a la lectura de los EEE, pudiendo considerarse en combinación con la retórica visual para alcanzar la convergencia sémica que valide la hipótesis sobre los propagandemas.

El estudio del significado intrínseco trasciende los datos empíricos, no siendo sistemático ni necesariamente consciente por parte del emisor, de tal modo que Panofsky define el objeto de la iconología como "aquellos principios subyacentes que ponen de relieve la mentalidad básica de una nación, de una época, de una clase social, de una creencia religiosa o filosófica, matizada por una personalidad y condensada en una obra" (ibídem: 49). Si la

\footnotetext{
1 Hay quienes, como Argan (1975), han encontrado paralelismos entre la teoría de Panofsky y el estructuralismo, mientras que Hasenmueller (1978) ha reconocido con matices ciertas coincidencias con la semiótica.
} 
percepción pura conduce al significado natural y la intelección al convencional, según Panofsky el significado intrínseco se capta mediante lo que llama:

nuestra intuición sintética [que] debe ser corregida por una investigación acerca del modo en que, bajo diversas circunstancias históricas, las tendencias generales y esenciales del espíritu humano se expresaron a través de temas y conceptos específicos. Esto significa lo que podría llamarse una historia de los síntomas culturales en general (ibídem: 57).

Panofsky no descarta la posibilidad de que en el fondo tales tendencias sean inmutables, pero no así la expresión de las mismas, que cambia de acuerdo con las coordenadas históricas de la creación artística. Por habitar en un terreno donde las actitudes subyacentes compartidas ponen en contacto a emisores y receptores, parece que, con toda su vaguedad, la iconología pudiera tener que ver con las CR del modelo de Pineda, en tanto derivan de las actitudes colectivas que eran objeto de la manipulación propagandística en la clásica definición de Laswell (1927: 627, en Pineda Cachero, 2006: 281). En esta línea afirmó Umberto Eco: "By 'rhetoric' I mean an art of persuasion which relies on endoxa, that is, on the common opinions shared by the majority of readers" (2003: 45). En el presente artículo, a la hora de abordar este terreno extratextual que consideramos relacionado con las CR y que puede extenderse hacia lo intuitivo, lo irracional y lo inconsciente, acudiremos tanto a la evidencia histórica como a teorías ya formuladas sobre la endoxa de la sociedad estadounidense, a la que estaba originalmente destinado el texto visual que es nuestro caso de estudio.

\section{Análisis del caso propuesto}

Aplicaremos el modelo sintetizado en el apartado previo al análisis de un caso particular de mensaje propagandístico: la ilustración de portada del comic book Human Torch Comics, no 12 (Marvel $^{2}$, verano de 1943), obra del ilustrador Alex Schomburg (véase la figura siguiente).

\footnotetext{
${ }^{2}$ Empleamos aquí la denominación por la que es conocida en la actualidad esta compañía.
} 


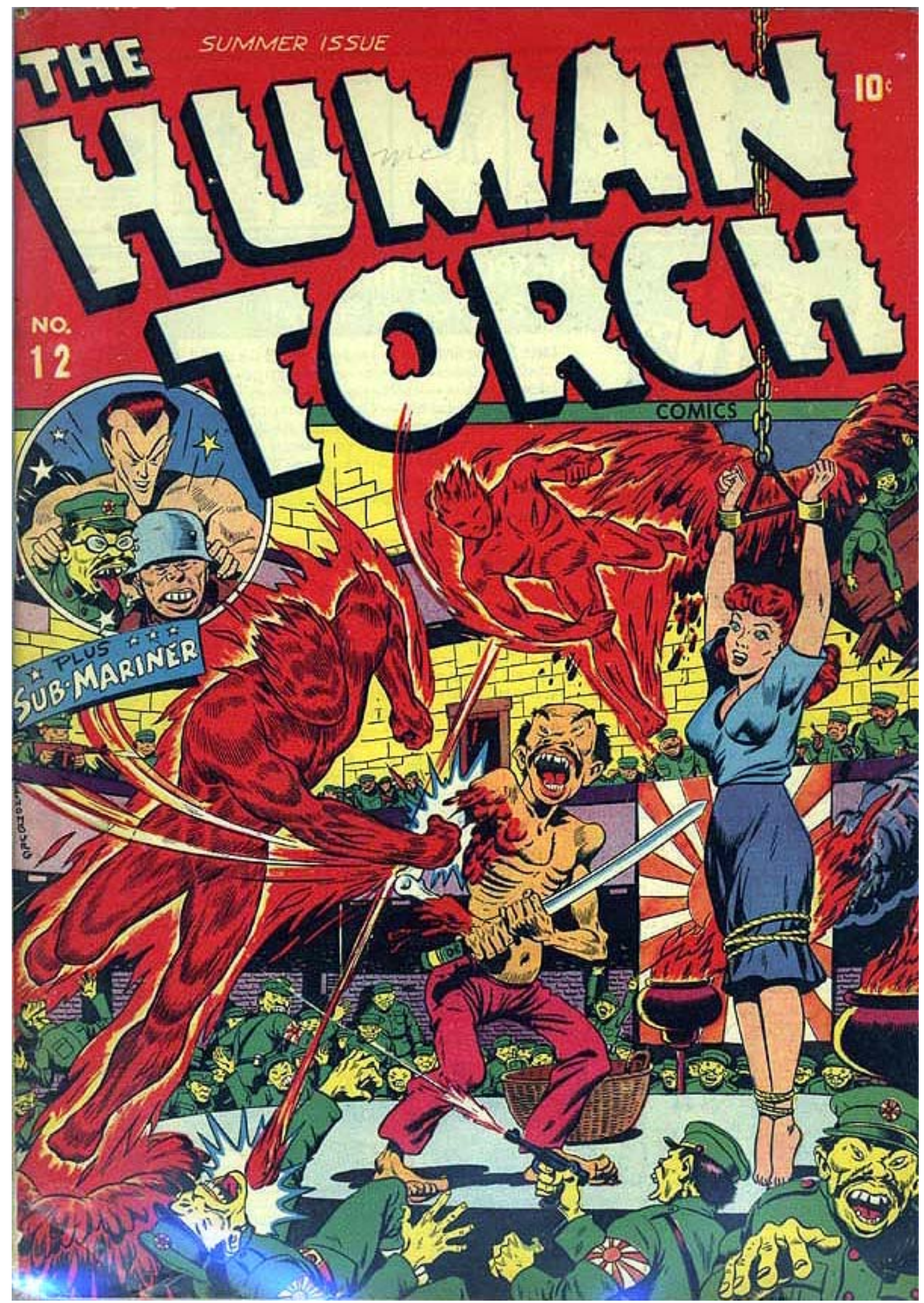




\subsection{Emisores, propagados y propagandemas}

El comic book es un formato de publicación integrado principalmente por historietas que la industria editorial estadounidense adoptó desde 1933. El gran impulso a esta industria llegó con la presentación del personaje Superman en Action Comics no 1 (DC ${ }^{3}$, junio de 1938). La popularidad de Superman supuso también la irrupción de todo un nuevo género narrativo basado en el tipo de personaje que representaba: el superhéroe. Los primeros años dorados del género coincidieron con la implicación de este país en la II Guerra Mundial, incluyendo el debate previo entre aislacionistas e intervencionistas. Estas circunstancias han movido lógicamente a establecer una relación cooperativa entre la actitud del país durante la guerra y las claves particulares de la narrativa de superhéroes. En ese sentido, algunos estudiosos han considerado que "the genre as a whole fed off of the American government's program of domestic propaganda" (Murray, 2000: 142). Tal afirmación debe ser matizada: en la ficción, los héroes de los comic books entraron en guerra mucho antes de que Estados Unidos lo hiciera oficialmente en la realidad ${ }^{4}$; y no existe constancia de dictado directo alguno desde el gobierno a las editoriales de comic books con fines propagandísticos, como sí los hubo a otros medios. De hecho, la OWI (United States Office of War Information) se planteó pronto la utilización de las historietas, pero sus estudios las encontraron poco útiles por su propensión a "hackneyed portrayals of patriotic ideals and overly stereotyped characterizations of the enemy as stupid and incompetent, and these depictions tended to lull viewers into complacency rather than prompting them toward greater effort" (Barkin, 1984: 115). Tal estilo propagandístico chocaba frontalmente con el hecho de que: "The official doctrine of President Franklin D. Roosevelt was that the makers of popular culture should contribute with a form of propaganda that informed rather than inflamed" (Strömberg, 2010: 42). En consecuencia, la "OWI ultimately decided to leave comics alone for the remainder of the war" (Barkin, 1984: 117), lo que no significó en absoluto que los comic books de superhéroes no continuaran entregados a su representación maniquea y triunfalista de la guerra.

Entre las editoriales de comic books, la de Martin Goodman, responsable de la publicación de la portada que nos ocupa, mostró especial interés por la intervención en la II Guerra Mundial antes de Pearl Harbor, a juzgar por sus portadas y sus historietas. Por esas fechas sus superhéroes -y los de otras compañías- tenían puestos sus puntos de mira en el conflicto en Europa ${ }^{5}$. Cuando se produjo el ataque japonés contra Pearl Harbor, la hostilidad de la nación se dirigió hacia el enemigo oriental. Sin olvidar a la Alemania nazi, los comic books se ensañaron especialmente con los asiáticos, un comportamiento no exclusivo de las publicaciones de historietas:

In the United States, as well as Britain and most of Europe, anti-Semitism was strong and [...] the Holocaust was wittingly neglected or a matter of indifference. Japan's aggression, on the

\footnotetext{
${ }^{3}$ Utilizamos aquí la denominación moderna de esta compañía.

${ }^{4}$ Véase Jiménez Varea, 2004: 154-158.

${ }^{5}$ En el caso de los comic books, resulta tentador achacarlo a que muchos profesionales de la industria fueran judíos que respondían de este modo a los desmanes antisemitas del régimen nazi.
} 
other hand, stirred the deepest recesses of white suprematism and provoked a response bordering on the apocalyptic (Dower, 1996: 72).

Ni siquiera hacía falta abrir los comic books para apreciar ese cariz de batalla del Armagedón que tenía la guerra, pues ya lo voceaban desde el exterior unas portadas que hacían las veces de auténticos carteles propagandísticos: "it is evident how much they resemble official propaganda posters from that era. The same rhetorical techniques and strategies were used in order to attract readers" (Strömberg, 2010: 42). Las publicaciones de Goodman son ejemplos de esta práctica, en especial aquéllas con portadas del artista Alex Schomburg.

Puesto que la OWI desechó la posibilidad de emplear los comic books como vehículos de propaganda, el caso que nos ocupa no responde a un encargo específico por parte de esta agencia, sino a una iniciativa privada, motivada en alguna proporción por la combinación de los sentimientos patrióticos y los imperativos comerciales de sus responsables dentro de la editorial ${ }^{6}$. Desde ese punto de vista, está claro que el gobierno de Estados Unidos no fue el emisor empírico del mensaje en cuestión, si bien sí fue, de acuerdo con los fines interesados de sus productores, el beneficiario del mismo, o sea el $\mathrm{PDO}(+)$, como uno de los bandos enfrentados en el escenario del océano Pacífico durante la II Guerra Mundial. Dicho efecto se produce como respuesta explícita a la existencia, asimismo manifiesta en el mensaje, de un $\mathrm{PDO}(-)$, que es su adversario, Japón, en lo que constituye un caso evidente de $\mathrm{P}_{\mathrm{r}}$. En cuanto a los ropajes ideológicos en que se envuelven los intereses del propagado para construir este mensaje propagandístico concreto, podemos postular como propagandema una noción acorde con el propio carácter reactivo de la modalidad de propaganda desplegada en el ejemplo: la venganza, retribución o respuesta de carácter violento. Lógicamente, este propagandema se presenta como consecuencia de la propia encarnación desfavorecedora, $\operatorname{PMA}(-)$, del PDO(-):

Por lo general, la forma de presentar ambos tipo de PMA (negativo y positivo) en la propaganda de reacción es: primero, el PMA(-)-que representa a la amenaza, el enemigo, el peligro, etc.-, y después, como reacción ante la amenaza, el PMA $(+)$, correspondiente al PDO $(+)$. De forma que si se produce el PMA $(-)$, aparece entonces el PMA $(+)$ para contrarrestarlo (Pineda Cachero, 2006: 261).

Se constituye así un enfrentamiento de propagandemas que puede, a su vez, descomponerse en oposiciones acción-reacción subordinadas sobre las que se apoya el ideologema principal de la retribución violenta en el que hemos querido resumir el mensaje. Si expresamos la propaganda de reacción en la forma " $P r=A+Z$, siendo ' $A$ ' el valor ideológico correspondiente al $\mathrm{PDO}(-)$ que es atacado propagandísticamente, y siendo ' $\mathrm{Z}$ ' el valor contrario e imputado al PDO(+)" (ibídem: 245), habríamos de localizar a través de la lectura de los EEE una serie finita de pares $(\mathrm{Ai}, \mathrm{Zi}$ ) homólogos de otros de propagandemas $(\mathrm{PMA}(-), \mathrm{PMA}(+))$ que lleguen a converger en el hipotético propagandema principal.

\footnotetext{
${ }^{6}$ Strömberg relaciona este afán propagandístico con las medidas de racionamiento del papel: "The comic book industry was actually able to boost its sales during World War II, because the help in the war effort meant that comic books were spared from paper recycling" (2010: 42). De haber sido realmente así, el gobierno habría propiciado, de manera indirecta pero efectiva, la emisión de esta propaganda.
} 


\subsection{Nivel de significación natural-denotativa de los EEE}

El texto visual que nos ocupa es una imagen fija y aislada, construida sobre un sistema semiótico bidimensional planario y cuya producción responde a una creación manual. Como dibujo coloreado, su iconicidad corresponde al octavo nivel de la escala de Moles (1981), dotada de un grado de analogía con sus referentes inferior a la de la imagen fotográfica de contrastes matizados. Frente a la fotografía, que es un "message sans code", Barthes consideraba que "la dénotation du dessin est moins pure que la dénotation photographique, car il n'y a jamais de dessin sans style" (1964: 46). Distinta cuestión es la reconocibilidad para el espectador de lo denotado, pues los dibujos pueden parecerse más a los schemata mentales del reconocimiento visual que las imágenes fotográficas (Ryan y Schwartz, 1956). La imagen fotográfica ofrece al receptor un estímulo más próximo al que ofrecerían directamente los sujetos en un espectáculo natural, pero el dibujo puede adelantar al espectador varias etapas en el proceso perceptivo. Que una cierta estilización favorezca la legibilidad depende de que suprima los rasgos poco característicos mientras que conserve e incluso acentúe los que sí lo son. Bien puede considerarse que así ocurre con el estilo cartoony, tal vez naïve, del autor de nuestra portada.

Es interesante detenerse brevemente en el hecho de que se trate de una imagen fija y única. La portada constituye un elemento paratextual respecto de las narraciones que se encuentran dentro del comic book. Mientras las historietas se apoyan en la secuencialidad de la imagen, las portadas son herramientas de reclamo del consumidor cuya naturaleza puede ser variada, así como su relación con el contenido de las publicaciones que las lucen. Esta portada pertenece a una de las categorías más comúnmente utilizadas: no representa escena alguna que se narre dentro del comic book, pero condensa en una imagen muchos de los principios genéricos y específicos del protagonista. Sin recurrir a la ilusión temporal inducida al lector por la secuencia visual, esta imagen constituye un resorte paranarrativo en tanto permite al espectador reconstruir una historia por mínima que sea.

Esa historia surge sin dificultad de la descripción en el nivel denotativo de su significado: dos formas humanoides voladoras y llameantes se abalanzan sobre un numeroso grupo de seres también humanoides, de epidermis llamativamente amarillentas y rostros simiescos casi idénticos. La más prominente de las imágenes de sustancia lingüística ${ }^{7}$, la cabecera de la colección que reza "The Human Torch", actúa como un texto de anclaje denotativo que identifica al personaje flamígero en primer plano como el héroe epónimo y, por extensión

\footnotetext{
7 Esta portada presenta una cierta escasez de textos escritos, que se limitan a la mencionada cabecera, la fecha de portada, el precio original de venta al público, ambos de relevo, más un cartucho anexo al inserto circular que anuncia la existencia en el interior del comic book de una historieta protagonizada por el Sub-Mariner, funcionado respecto a esta imagen de manera similar a la cabecera en relación con la imagen principal. En cuanto a su contenido, ha lugar a poca o ninguna discusión sobre la retórica literaria de estos textos, mientras que las cualidades plásticas de sus significantes son susceptibles de una manipulación en la que cabe mencionar la estilización llameante de la cabecera, que refuerza a través de esta rima icónica su propia significación y su relación directa con el personaje epónimo.
} 
para el lector iniciado, a su acompañante como Toro ${ }^{8}$. Un papel similar, funcionando por convención como el texto lingüístico, desempeña la Kyokujitsu-ki, la bandera de guerra del ejército imperial japonés, que aparece repetidamente. Gracias a este símbolo podemos identificar inequívocamente a los personajes de piel amarilla como militares japoneses, que, uniformados de verde, resultan indistinguibles entre sí. La única excepción corresponde al que aparece en la zona central de la imagen, con el torso descubierto, descalzo, con pantalones rojizos y blandiendo un sable. La Antorcha Humana lo agarra por el brazo derecho, quemándoselo hasta el hueso, mientras Toro dirige sus llamas contra la masa indiferenciada. Junto a la Antorcha y el japonés abrasado, completa el centro de la composición la figura de una fémina de piel rosada y pelo rojizo, maniatada y suspendida del techo. Si, empleando la terminología de Panofsky, hasta ahora la descripción se ha limitado a lo fáctico, en lo expresivo cabe destacar la mueca agonizante del japonés semidesnudo, así como las de terror de sus congéneres. Más difícil es determinar si la expresión boquiabierta de la prisionera responde a miedo ante la amenaza del sable, sorpresa por la aparición de los dos héroes o asombro ante el castigo infligido a su verdugo. En cuanto a la Antorcha Humana, su expresión resulta inescrutable, sus rasgos faciales ocultos tras las llamas, mientras que en el caso de Toro, puede apreciarse un atisbo de sonrisa a través de ellas.

Considerando el conjunto de lo descrito más arriba es razonable deducir que la escena representa a las antorchas humanas impidiendo que la mujer sea objeto de una agresión a manos de uno de los japoneses mientras los otros observan.

\subsection{Nivel de significación convencional-connotativa de los EEE}

La organización retórica de la imagen comienza en el ámbito plástico. Según el Groupe $\mu$ (1993, capítulo quinto), hay tres parámetros del signo plástico con sus correspondientes unidades semióticas: textura (dos texturemas: el patrón que se repite y la ley de repetición), forma (tres formemas: posición, dimensión y orientación) y color (tres cromemas: dominancia cromática o tonalidad, saturación y brillo). En el caso que nos ocupa, lo más destacable en cuanto a la textura es cómo su aspecto liso, de colores aproximadamente planos $^{9}$ otorga preeminencia al carácter bidimensional de la imagen, lo que a su vez contribuye al esquematismo de la representación y a la inmediatez comunicativa de la misma.

\footnotetext{
${ }^{8}$ Puede considerarse que la integración de tal información aleja la lectura del nivel cero de interpretación que Panofsky atribuía a la descripción pre-iconográfica, pero realmente sirve tan sólo para asistir la denotación y, en el caso concreto del presente texto, para evitar el tedio, la posible confusión y la escasa operatividad que resultaría de referirnos repetidamente a unas figuras humanas ardientes, llameantes o flamígeras genéricas. Saber que la Antorcha Humana y su compañero están revestidos de llamas que no sólo no les dañan sino que pueden controlarlas e incluso volar gracias a ellas, cambia radicalmente la comprensión aun en el nivel denotativo respecto a la que se tendría en caso de asignar a estas representaciones como referentes dos seres humanos cuyos cuerpos arden mientras caen. Obviamente, la primera opción de atribución de significado implica un ingrediente convencional que no es necesario en la segunda.

${ }^{9}$ Una marca de estilo característica del portadista Schomburg fue su empleo del aerógrafo en el coloreado de sus dibujos, una técnica que permite la gradación de los tonos. Sin embargo, no se aprecia el resultado del aerógrafo en la portada en cuestión, cuyos colores aparecen planos, como se comentaba arriba.
} 
Los formemas en su conjunto ordenan la mirada del receptor instalando una cierta jerarquía de la información contenida en la ilustración: la posición dentro del espacio de la representación configura su significante en función de la variable centralidad-marginalidad, de modo tal que su significado emana de la estabilidad que otorga una composición centrada frente a otra que no lo sea; el significante de la dimensión surge de las posibles articulaciones de la oposición básica grande-pequeño, encontrando entonces su significado en la dominancia del tamaño; por último, la expresión de la orientación se funda en el binomio centrífugo-centrípeto y su contenido es el equilibrio estable (mínimo potencial dinámico), inestable (máximo potencial dinámico) o ausente (dinamismo) correspondientes a las aproximaciones a la horizontalidad, la verticalidad o la diagonalidad, respectivamente. Aplicando todo lo anterior a la portada, observamos que en el centro de la imagen, tal como puede quedar delimitado por la clásica norma de los tercios, se encuentran tres figuras cuya principalidad viene subrayada también por la dominancia que les concede su mayor tamaño, así como por la orientación centrípeta de los elementos en la composición. Concretamente, en el propio centro de la imagen se encuentra el motivo más sensacional de la misma: el puño ardiente de la Antorcha Humana lesionando el brazo del japonés. Además, la orientación oblicua de las dos antorchas humanas funciona como perturbación dinámica, transmitida al propio japonés central, sobre el estatismo cargado de tensión marcado por la verticalidad de la prisionera encadenada. Evidentemente, en el terreno de lo icónicofigurativo, diversos elementos cooperan en la organización de la imagen debida a los parámetros plásticos: las miradas de la mayor parte de los japoneses, así como los disparos de algunas de sus armas, refuerzan el carácter centrípeto de la composición; las poses de las antorchas son en sí mismas reconocibles como propias del movimiento, sumándose así al dinamismo puramente formal de su diagonalidad; y el mayor tamaño que permite a los electos centrales dominar la representación tiene sentido en el plano figurativo como resultado de la perspectiva.

Respecto al tercer parámetro plástico, lo mas razonable es acogerse a las conclusiones de Wright y Rainwater (1962) sobre las asociaciones suscitadas por los colores: "[...] /luminosidad/ y /saturación/ inducen una respuesta semiótica profunda, general e intersubjetiva, mientras que la /dominancia/ estaría sobre todo ligada a experiencias personales, de las que sólo una parte es común a todos: en esta medida, la /dominancia/ construye idiolectos" (Groupe $\mu$, 1993: 213). No existe un uso subrayado de saturación (máxima) y brillo (uniforme) en la cuatricromía de la portada, por lo que sólo discutiremos la dominancia, sobre la cual, por otra parte, no tiene sentido abordar las respuestas debidas a "experiencias personales" en el ámbito de la comunicación masiva. Así pues, reservaremos el análisis de la codificación cromática en la imagen al ámbito de las convenciones culturales de naturaleza simbólica.

En la imagen principal de la portada predominan cuatro colores: verde, amarillo, rojo y azul. El primero se encuentra sobre los uniformes dibujados, reproduciendo aproximadamente el color de éstos en la realidad, por lo que podríamos atribuir al verde una función meramente 
referencial; no obstante, interesa tener en cuenta posibles simbolismos que contribuyan a la construcción del japonés como propagado negativo, como: "En el arte medieval, el [verde] puede tener [...] significado negativo como color del veneno y de un brillo amenazador" (Oesterreicher-Mollwo, 1983: 224). La carga cultural desfavorecedora del amarillo, que colorea la epidermis de los japoneses y los muros, se evidencia en que sea sinónimo de "cobarde" en el inglés americano, también con precedentes en la iconografía medieval: "Durante la Edad Media predominan las interpretaciones negativas: [amarillo] como color de la envidia (también en el Alto Egipto) o como color vergonzante de judíos, herejes y prostitutas" (ibídem: 190). Su uso en esta imagen responde además a una tradición de clasificación de las razas humanas en función del supuesto color de la piel que, a su vez, asigna rasgos caracterológicos y morales. Así, Carl von Linneo ${ }^{10}$ escribió que los asiáticos en general son "Sallow, melancholy, stiff [...] Severe, haughty, avaricious [...] Ruled by opinions", mientras que los europeos son "White, sanguine, muscular [...] Gentle, acute, inventive [...] Governed by laws" (en Smedley, 1993: 164). El color rojo se halla sobre las representaciones de las llamas y las de los soles de las banderas, ligando así fuego y sol en consonancia con algunas de las clásicas acepciones simbólicas de este color que son aquí de especial pertinencia: "color de la guerra, del poder destructor del fuego, del correr de la sangre, del odio [...] el verdugo medieval, como señor sobre vida y muerte, llevaba indumentaria roja" (Oesterreicher-Mollwo, 1983: 190). Por último, el azul que se encuentra en dos tonos sobre el ropaje de la prisionera puede leerse como el color del "manto de María, como símbolo de pureza" (ibídem: 31).

En el terreno figurativo, la escena de rescate heroico que representa la portada hace razonable ubicarla en el linaje de lo que Calvo Serraller ha considerado el "género [pictórico] por excelencia, el más apreciado ya desde la propia antigüedad: la representación de acciones humanas memorables, protagonizadas por dioses o por héroes -género que, posteriormente, a partir del renacimiento, se dio en llamar 'pintura de la historia'"' (2005: 9). Uno de los principales cultivadores de este género fue el pintor inglés Joshua Reynolds, entre cuyas reflexiones sobre lo que denominó "the Grand Style"11 se incluye la siguiente, próxima a algunas preocupaciones que podría tener un emisor propagandístico, relativa al tema del cuadro:

[...] no subject can be proper that is not generally interesting. It ought to be either some eminent instance of heroic action, or heroic suffering. There must be something either in the action, or in the object, in which men are universally concerned, and which powerfully strikes

10 En su Sistema Naturae (1758-1759) este naturalista dividió la especie humana en cuatro grupos continentales etiquetados por el color de la piel: blanca (Europeanus), amarilla (Asiaticus), roja (Americanus) y negra (Africanus).

${ }^{11}$ Algunas de las recomendaciones estéticas de Reynolds refuerzan la relación que proponemos entre este género pictórico y la portada, sobre todo si se comparan con nuestras observaciones previas sobre los parámetros plásticos. En relación con la composición aconsejó una subordinación al motivo central: "All smaller things, however perfect in their way, are to be sacrificed without mercy to the greater" (1831: 25). También son particularmente oportunas sus instrucciones para el uso del color: "Grandeur of effect is produced by two different ways [...] One is, by reducing the colours to little more than chiara oscuro $[\ldots]$ and the other, by making the colours very distinct and forcible [...]; but still, the presiding principle of both those manners is simplicity. Certainly, nothing can be more simple than monotony; the distinct blue, red and yellow colours [...] have that effect of grandeur [...] Perhaps these distinct colours strike the mind more forcibly, from there not being a great union between them" (1831: 27$)$. 
upon the public sympathy. Strictly speaking, indeed, no subject can be of universal, hardly can it be of general, concern; but there are events and characters so popularly known in those countries where our art is in request, that they may be considered as sufficiently general for our purposes (1831: 24).

Reynolds concretaba que los temas extraídos de la historia antigua grecorromana y los de la Biblia eran los que tenían mayor radio de interés en los países donde existía demanda de la obra de la Royal Academy of Arts. Trasladando la reflexión del pintor a esta portada de comic book, cabe preguntarse sobre qué temas y motivos visuales se apoya para pulsar las fibras adecuadas del receptor medio estadounidense con el fin de ejercer eficazmente su función propagandística. Tales consideraciones trasladan a las condiciones de recepción -en cierto modo, la iconología-, que abordaremos en el siguiente apartado, pero sí es importante determinar aquí la significación cultural de los motivos y la gesta heroica representados que puedan conducir a aquéllas.

Para empezar, son necesarias unas nociones mínimas sobre el género de los superhéroes, así como sobre los especimenes del mismo que protagonizan esta portada. Peter Coogan define al superhéroe, y por ende al género, como:

A heroic character with a selfless, pro-social mission; with superpowers [...]; who has a superhero identity embodied in a codename and iconic costume, which typically express his biography, character, powers, or origin [...]; and who [...] can be distinguished from characters of related genres [...] by a preponderance of generic conventions (2006: 30).

Estos ingredientes se habían reunido de modo relativamente novedoso en el modelo del género, Superman, pero no eran, en absoluto, originales, pues surgían de la confluencia de otras tradiciones de la narrativa popular de fantasía y/o aventura: "the science-fiction superman, beginning with Frankenstein (1818); the dual-identity avenger-vigilante, beginning with Nick of the Woods (1835); and the pulp übermensch, [...] beginning with Tarzan of the Apes" (ibídem: 126). En cuanto a su aspecto, tratándose de un medio donde la imagen figurativa juega un papel principal y donde primaba la caracterización inmediata por economía de espacio, el superhéroe se sumó a la tradición clásica de la kalokagathia, equiparando bondad, belleza y verdad, una pauta común al grueso de la cultura popular: "Comic heroes are the apex of heroism, with all the prerequisites of strength, brains, handsomeness, and appeal to women that are incumbent upon juvenile heroes" (Sundell, 2000: 29$)^{12}$.

Las recombinaciones de las influencias culturales que habían dado lugar a Superman y las variaciones más o menos obvias sobre éste comenzaron a llegar en la forma de un variopinto aluvión de superhéroes a partir de 1939. Entre los empresarios que advirtieron muy pronto el potencial que tenía el formato comic book encauzado en el género superheroico estaba Martin Goodman, cuya compañía se dedicaba a la publicación de pulps. Su incursión inicial en el campo de los comic books fue Marvel Comics, no 1 (Marvel, octubre de 1939), donde

${ }^{12}$ El guionista de historietas de superhéroes Abner Sundell publicó en 1942 un texto para instruir a los aspirantes en las convenciones del género. 
presentaba una primera hornada de sus propios superhéroes, incluyendo la Antorcha Humana (The Human Torch) ${ }^{13}$. Tenía suficientes elementos en común con Superman como para ganarse el favor de un número importante de lectores, pero difería lo suficiente como para poder ser considerada una variación significativamente innovadora de la fórmula del superhéroe. Su creador, Carl Burgos, había bebido directamente de la mencionada corriente de los superhombres de la ciencia ficción, que se remonta, al menos, hasta la criatura de Frankenstein. Su artífice en la ficción, el Profesor Horton, lo describe como:

[...] a synthetic man -an exact replica of a human being. [...] Even I fear the monstrosity which I've created!! [...] Something went wrong with my figurings somewhere. Every time this robot, the Human Torch, contacts oxygen in the air, he bursts into flame! (de la página inicial de su primera historieta, en Marvel Comics, no 1).

Sin embargo, bajo su superficie llameante, como corresponde a un héroe popular, el personaje no es en absoluto monstruoso y muy pronto adquiere la habilidad de inflamarse a voluntad, pasando de producto de la ciencia descontrolada a logro de la moderna civilización estadounidense, cuyos valores hace suyos. Frente al primitivismo del japonés armado con un sable, el superhéroe se presenta como la encarnación viviente del progreso tecnológico occidental.

A medida que el género de los superhéroes se definía más nítidamente, las historietas de la Antorcha Humana incorporaron algunas de las principales convenciones genéricas: el personaje adopta el nombre alternativo de Jim Hammond (Marvel Mystery Comics, no 4, Marvel, febrero de 1940); se alinea claramente del lado del sistema, hasta el punto de unirse como agente a la policía de Nueva York en su apariencia humana, consolidando así su doble identidad a la vez que su misión pro-social (Marvel Mystery Comics, no 7, Marvel, mayo de 1940); y se le llega a unir como compañero permanente de aventuras Toro, un joven con sus mismos poderes (Human Torch Comics, no 2, Marvel, otoño de 1940), siguiendo la tradición de los sidekicks, introducida en el género de los superhéroes con el popular Robin, escudero de Batman. Dentro de la producción de la editorial Marvel durante la etapa que nos ocupa, la Antorcha humana fue el primer personaje que dio nombre a una colección y fue el que apareció en más ilustraciones de portada.

En el conjunto del género, este superhéroe no se encontró en la liga de los mayores éxitos, donde competían Superman, Batman o el Capitán Marvel, pero gozó de una considerable popularidad durante la II Guerra Mundial, merced, sin duda, a sus distintivos poderes y aspecto. Como uno de los cuatro elementos en las concepciones clásicas del universo, el fuego ha acumulado una enorme riqueza simbólica, incluyendo relaciones con el poder, la ira y la justicia divinos. En la Biblia son numerosas tales asociaciones: "The god of the Hebrews manifested himself in a burning bush, as a pillar of fire and as a fiery presence on Mt Sinai.

13 Otro era el Sub-Mariner, que aparece en la imagen secundaria inserta en la portada que estudiamos. Creado por el historietista Bill Everett, fue uno de los superhéroes más populares de su editorial en los años cuarenta, junto con la Antorcha Humana y el Capitán America (Captain America Comics, no 1, marzo de 1941). 
The 'pentecostal fire' that descended on the brows of the apostles, was a manifestation of the Holy Ghost. Fire is purificatory in the Christian doctrine of purgatory and is retributive in hell" (Hall, 1996: 100-101). Dentro del monoteísmo judeocristiano también están relacionados con el fuego algunos ángeles:

There are two kinds of angels mentioned in the Bible, the seraphim and the cherubim, and in later iconography they were associated respectively with tongues of flame and with birds in the sky. [...] In medieval pictures where angels appear, you will see the seraphim coloured red and the cherubim coloured blue (Frye y Macpherson, 2004: 74-75)

En La Ilíada, abundan las alusiones al fuego en referencia al valor y la fuerza de los guerreros, cualidades de la que es el epítome Aquiles, al que se llega a describir como si de una antorcha se tratara (Canto XVIII, 207-214). En el mismo poema homérico Hefestos utiliza su poder sobre el fuego para ayudar a los griegos en la guerra, al igual que la Antorcha Humana lo hace por los aliados en los comic books. Así, de acuerdo con las iconografías más difundidas en occidente, este superhéroe, en su apariencia ígnea, ejemplifica especialmente bien las resonancias religiosas del género: "Powers that the culture had earlier reserved for God and his angelic beings are transferred to an Everyman, conveniently shielded by an alter ego" (Jewett y Lawrence, 2002: 44).

De acuerdo con las convenciones del género, al superhéroe se opone la figura del villano, cuyo enfrentamiento moral y físico es consecuencia necesaria de la misión pro-social del primero. Visualmente, la fealdad del villano se contrapone a la belleza del héroe como manifestación física de su maldad: "The villain must represent all vices, all that is evil, at a glance. Artistically he is a caricature of 'bad'. The juvenile mind will thus identify at an immediate glance the battle between good and evil" (Sundell, 2000: 31). De este modo, el recurso al eje héroe-villano genera a través de una figura retórica de contraste una ordenación axiológica que se traduce en nuestro modelo en los propagandemas opuestos de bondad-belleza $(+)$ vs. maldad-fealdad (-). En la portada ocupan este segundo lugar los japoneses, cuya apariencia física responde a unas arraigadas pautas de estereotipos racistas anti-asiáticos, incluyendo el color amarillo de la piel al que ya nos hemos referido antes. Desde la llegada de los primeros inmigrantes chinos a California en la segunda mitad del

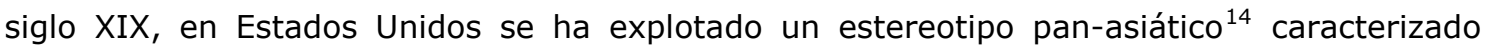
porque: "Many of the stereotypical traits associated with Asians in the American press were done in order to show Asians as less than human" (Strömberg, 2010: 16). En su actualización con motivo de la II Guerra Mundial, los dibujantes desfiguraron la imagen del japonés sistemáticamente para asemejar una gama de animales despreciados por la mentalidad estadounidense -ratas, cucarachas, serpientes...-', pero, como ha señalado John

\footnotetext{
${ }^{14}$ Es significativo de la tradición pan-asiática del estereotipo que, pocos días después del ataque a Pearl Harbor, la revista Time se esforzara por educar a sus lectores para distinguir a los amigos chinos de los enemigos japoneses. Como consecuencia se explicitaban dos subestereotipos, uno favorable y otro negativo ("How to Tell Your Friends from the Japs", en Time, 22 de diciembre de 1941, p. 33).
} 
Dower $^{15}$ : "Among western political cartoonists, the simian figure was surely the most popular caricature for the Japanese" (1996: 175). En marcado contraste con la cultura oriental, en occidente el mono, como motivo y tema, ha estado marcado tradicionalmente por un signo negativo: "The Greeks and the Romans considered apes ridiculous, strange, ugly, and somewhat dangerous, and 'ape' was a common term of abuse" (Ferber, 2007: 12); "In the West, medieval and Renaissance man saw in the ape an image of his baser self. Thus it came to symbolize Lust, one of the Seven Deadly Sins, idolatry and vice in general" (Hall, 1996: 10). El estereotipo del varón asiático heredó esas connotaciones no sólo para ridiculizarlos sino también para mostrarlos como una amenaza para la moral occidental, particularmente en lo sexual: "they were misogynists and prone to be disrespectful towards women. They were also portrayed as predators of white women, an image used extensively during World War II when Japan became a military enemy" (Strömberg, 2010: 17). La imagen ominosa del oriental enlaza con uno de los arquetipos más antiguos de occidente, integrado plenamente en la cultura de masas contemporánea, el Peligro Amarillo, dentro del que se distinguen dos modalidades:

The first is of Asians as a group. The Yellow Peril stereotype of Asians en masse is of a faceless horde of decadent and sexually rapacious barbarians. That stereotype [is] still active in the West [...] the second Yellow Peril stereotype [is] that of the individual evil genius intent on destroying the West (Nevins, 2003: 187).

El origen de la primera categoría se halla en las sucesivas invasiones de territorios occidentales por pueblos de procedencia oriental: los visigodos en el siglo III; los hunos en el siglo IV y, sobre todo, en el siglo V, comandados por Atila; la conquista de gran parte de Asia, el Medio Oriente y la incursión en Europa oriental por el ejército mongol de Gengis Khan en el siglo XIII; y las similares proezas militares de Tamerlán entre 1399 y 1403. Aun sin fundamentos reales, el temor a nuevas invasiones sobrevivió en los siglos siguientes y fue reavivado en Estados Unidos a finales del siglo XIX cuando se extendió entre los ciudadanos blancos la percepción de que los inmigrantes chinos competían con ellos en un mercado laboral disminuido por la recesión económica. Consecuencia de estos miedos fueron el Acta de Exclusión China (1882) y la llamada Acta Scott (1888) que paralizaron efectivamente la migración desde China hacia el país norteamericano. Pero también mantuvo su vigencia la idea de una invasión militar, como atestiguan la popularización del término "Peligro Amarillo" por el káiser Guillermo II en $1895^{16}$ y, particularmente en Estados Unidos, la gran repercusión de la obra The Yellow Peril; or, Orient vs. Occident (1911), donde en la tradición profética tan cara al anti-intelectualismo estadounidense, el autor, G.G. Rupert,

\footnotetext{
15 En sus escritos de 1986 y 1996, este profesor de Estudios Japoneses expone mecanismos racistas de generación de odio y total ausencia de empatía con el enemigo, tanto desde el bando estadounidense como desde el japonés.

${ }^{16}$ Por encargo del káiser y motivada por el desenlace de la primera guerra sino-japonesa (1894-1895), el artista Hermann Knackfuss dibujó una viñeta alegórica apoyada por la leyenda "Völker Europas wahret eure heiligsten Güter", pero más conocido por la denominación de "Gelbe Gefahr" (véase, por ejemplo, Tsu, 2005: 80). Iconográfica y semánticamente, la imagen presenta varios puntos en común con la portada que estudiamos: las personificaciones en figuras femeninas de varias naciones occidentales (Britania, Marianne, Germania...) en actitud temerosa; probablemente el arcángel Miguel, armado con una espada flamígera, advirtiendo a las anteriores; una personificación del enemigo oriental en la forma de Buda que se aproxima desde la lejanía.
} 
interpretaba "los reyes del Oriente" del Apocalipsis (16.12) como un eje integrado por China, India, Japón y Corea que habría de enfrentarse por la hegemonía mundial con Gran Bretaña y Estados Unidos (Rupert, 1941: 9). En su versión masiva, el Peligro Amarillo se encuentra en la portada en la forma de la horda uniformada que sufre las llamas de Toro. Su aspecto idéntico responde al afán generalizado de presentar a los japoneses como una sola cosa, sin identidades individuales, "photographic prints off the same negative", tal como se expresara en el documental propagandístico Know Your Enemy -Japan (Frank Capra, 1945). Tal énfasis en el colectivismo japonés se erige en polo de unos de los pares de propagandemas secundarios de la portada en oposición al individualismo implícito en el mito del superhéroe estadounidense sobre el que recae la misión de salvar a un sistema impotente ${ }^{17}$.

La mujer prisionera ocupa el lugar común en la narrativa popular de aventuras de la damisela en apuros, una función desempeñada con frecuencia por la novia eterna del héroe: la Jane Porter de Tarzan, la Olive Oyl de Popeye o la Lois Lane de Superman, por señalar unos pocos ejemplos. Más que ningún otro, este tipo de personaje presenta la vulnerabilidad de la que el superhéroe carece:

While a hero himself cannot be hurt by bullets, these same bullets can kill his sweetheart. Thus suspense grows from danger in which important sub-characters are placed, not upon the dangers which threaten the hero himself -except how these dangers threaten him in relation to the accomplishment of his task, which very often is the rescuing of the sub-character (Sundell, 2000: 32).

La doncella a merced de sus captores simboliza a esa sociedad que no se vale por sí misma y debe ser rescatada por el héroe, acogiéndose a la costumbre de las personificaciones patrióticas en figuras femeninas, como la misma Columbia representativa de Estados Unidos $^{18}$. Como el héroe y a diferencia del villano, es bella y, por tanto, buena, además de blanca -también el héroe aunque no sea evidente cuando está "encendido"- estableciendo aun otro contraste: whiteness (+) vs. nonwhiteness (-). Además, como ya se ha señalado, el azul de la indumentaria femenina connota la pureza virginal de su portadora, lo que podemos asociar con la figuración colonialista del asentamiento como "erotics of ravishment" de la tierra feminizada (McClintock, 1995: 3). Este concepto es clave para la comprensión de la significación simbólica de la acción representada en la portada, sobre todo si se tienen en cuenta la imagen del asiático como depredador sexual de mujeres blancas y el valor simbólico de la espada esgrimida por el verdugo japonés: "interpretada negativamente, simboliza los horrores de la guerra [...] En diversos contextos puede ser también símbolo fálico" (Oesterreicher-Mollwo, 1983: 94).

\footnotetext{
17 "A community in a harmonious paradise is threatened by evil; normal institutions fail to contend with this threat; a selfless superhero emerges to renounce temptations and carry out the redemptive task; aided by fate, his decisive victory restores the community to its paradisiacal condition; the superhero then recedes into obscurity" (Jewett y Lawrence, 2002: 6).

18 "In anthropology, woman corresponds to the passive principle of nature. She has three basic aspects: [...]; second, as the mother, or Magna mater (the motherland, the city or mother-nature)" (Cirlot, 2001: 376).
} 
Al dibujar el rescate de la joven a merced de sus captores, Schomburg estaba realizando su enésima versión de un tema con el que tanto él como numerosos colegas suyos habían adornado -y seguirían haciéndolo- las cubiertas de muchos comic books. Su antecedente directo se encontraba en el motivo de la bella y la bestia, habitual de las cubiertas de los llamados weird menace o shudder pulps. Tales imágenes reflejaban fielmente el contenido del subgénero:

bizarre, seemingly unexplainanable, deaths, ghostlike creatures, and frightening fiends, in a clothing setting of dreary houses, dark caves, dark forests, of devil cults and demoniac evildoers, of heroines under dire threat, and heroes pitted against seemingly hopeless odds (Jones, 1978: xv).

Entre sus más destacados cultivadores se encontraba la propia editorial de Martin Goodman $^{19}$, si bien su iniciador había sido el editor de Dime Mystery Magazine (Popular Publications) Henry Steeger, quien admitía: "My inspiration was the Grand Guignol Theater in Paris" (en ibídem: 6). A su vez, estas obras sensacionalistas en las que víctimas inocentes, en su mayoría mujeres, eran objetos de lascivia, tortura, mutilaciones y, por fin, asesinato, actualizaban la tradición del relato gótico. Este género que gozó de gran popularidad en Europa y Estados Unidos se caracteriza por su emplazamiento en algún recinto apartado, repleto de pasadizos e imaginería arcaizante, donde una doncella es amenazada de violación y/o muerte por un villano que representaba para la cultura contemporánea al Otro:

The term [Gothic] came into common use in the eighteenth century to denote the opposite of Western Europe, of civilization, of reason and order. In a Protestant England, self-forgingly itself as the centre of the modern world [...], the Gothic [...] stands for everything not: not modern, not enlightened, not free, not protestant, not English (Luckhurst, 2005: x).

De hecho, la naturaleza exótica del villano gótico se encuentra en la raíz del Peligro Amarillo en su modalidad de genio malvado que pretende conquistar Occidente. A finales de la era victoriana, lo gótico resurgió en el marco de la nueva literatura de masas conformada por novelas de un solo volumen y revistas de relatos cortos. Una de sus principales incorporaciones fue el supervillano oriental, conocido sobre todo por la figura del Dr. Fu Manchu (Arthur Sarsfield Ward "Sax Rohmer", 1911), si bien había contado con varios predecesores, especialmente el Dr. Yen How (The Yellow Danger, M.P. Shiel, 1898): un intelectual de ascendencias china y japonesa que, tras ser rechazado por una mujer blanca, reúne los ejércitos de China y Japón en una guerra mundial contra la raza blanca. Fu Manchu y un sinfín de sicofantes suyos se convirtieron en contrincantes habituales de los héroes de la cultura de masas, sin que las historietas, primero de periódicos y más tarde de comic books, fuesen excepciones. Tras el ataque a Pearl Harbor, la figura del Peligro Amarillo se concentró naturalmente en el contendiente japonés, mientras que se descargaba del anatema por unos años al aliado chino. En cierto modo, la portada que estudiamos involucra

${ }^{19}$ Goodman le dedicó la línea de publicaciones denominada Red Circle, de la que se ha escrito: "Readers were left in no doubt about the contents of the magazine because of the captive girls and malevolent fiends illustrated on the [...] brilliantly colored cover pictures of terrified beauties and the madman who wished them nothing but ill" (Haining, 2000: 148). 
tanto al Peligro Amarillo en su sentido de horda, como al villano individual, pues separa a uno de la masa para hacerlo objeto del ataque singular del protagonista. De ese modo, la imagen refiere al motivo clásico de la princesa rescatada de un monstruo por un héroe, de la que pueden encontrarse numerosísimos ejemplos durante siglos: Perseo a bordo de Pegaso desciende del cielo para salvar a la encadenada Andrómeda de un monstruo marino; Heracles libera a Hesíone de Troya, hija del rey Lameodonte, de su cadenas y mata a la criatura que la amenaza; en la epopeya hindú Ramayana, el héroe Rama, con la ayuda del dios-mono Hanuman, acude al rescate de Sita, abducida por el rey-demonio Ravana; la leyenda nacional inglesa de San Jorge y el dragón; las innumerables variaciones sobre el tema en los cuentos populares y en las novelas de caballería. Se trata de un tema imperecedero al que los creadores de relatos no dejan de recurrir, como comentó Eco respecto a James Bond, ligando directamente el mito del rescate del dragón con el del Peligro Amarillo:

Bond is the knight and the villain is the dragon; [...] lady and villain stand for beauty and the beast; Bond restores the lady to the fullness of spirit and to her senses -he is the Prince who rescues Sleeping Beauty; between the Free World and the Soviet Union, England and the nonAnglo-Saxon countries is realised the primitive epic relationship between the Privileged Race and the Lower Race, between White and Black, Good and Bad. [Ian] Fleming is a racist in the sense that any artist is one if, to represent the Devil, he depicts him with oblique eyes (Eco, 2003: 45)

En la cultura occidental, el dragón se erige como bestia predilecta para encarnar al enemigo, como ya señalara Joseph Campbell: "This formula, indeed, of the shining hero going against the dragon has been the great device of self-justification for all crusades" (Campbell, 2004: 315). Por su parte, Estados Unidos llevaba utilizando esta fórmula desde antes de su independencia nacional para demonizar a su primer gran Otro: el nativo norteamericano.

En su Magnalia Christi (1702), una de las figuras religiosas más relevantes del puritanismo genético del país norteamericano, Cotton Mather, se refirió a los originales habitantes de aquellas tierras como "generations of the dragon" (en Slotkin, 1973: 155), arrojando así sobre ellos toda la carga simbólica de los enemigos del pueblo elegido de Dios. La misma obra incluía material perteneciente a la que se considera "the first coherent myth-literature developed in America for American audiences" (ibídem: 95), las narrativas de cautiverio donde mujeres blancas eran secuestradas por indios y obligadas a vivir entre ellos. Este género gozó de enorme popularidad entre los pobladores blancos de Norteamérica, desde la aparición de $A$ Narrative of the Captivity and Restoration of Mrs. Mary Rowlandson (Mary Rowlandson, 1682) hasta el cierre de la frontera estadounidense a finales del siglo XIX. Supuestamente históricos o declaradamente ficticios, se trataba de relatos alegóricos en los que la desdichada cautiva representaba a toda la sociedad asentada en las tierras extrañas y las pruebas que sufría eran las tribulaciones de todo aquel colectivo. Al principio, la víctima del cautiverio había de buscar su propia salvación, pero tras un tiempo se introdujo en estas historias un giro cualitativamente distinto: la responsabilidad del rescate se desplazó a una figura masculina, retomando la tradición clásica del matador de dragones y verificando la mencionada estrategia de justificación de toda cruzada. Precisamente, entre los ejemplos 
más brutales de esta "regeneration through violence" (ibídem) se encontró una de las fuentes del género superheroico indicadas por Coogan, el protagonista de la novela Nick of the Woods (Robert Montgomery Bird, 1837): un cuáquero sicótico que vaga por los bosques asesinando sádicamente a indios para vengar las muertes de sus familiares, a quienes no había sido capaz de salvar. Este espíritu, según Susan Faludi, explica sucesivos episodios de la historia estadounidense: "The humiliating residue still circulates in our cultural bloodstream, awaiting provocation to bring it to the surface. And with each provocation, we salve our insecurities by invoking the same consoling formula of heroic men saving threatened women" (2007: 215). La respuesta al ataque japonés no fue una excepción y generó de inmediato su propia llamada a la retribución violenta "Remember Pearl Harbor!", reminiscente de otros tantos gritos de batalla que eximían a sus seguidores de toda responsabilidad por la brutalidad de sus actos. En definitiva la portada de Schomburg funciona como un potente aparato de axiologización al encajar en un esquema simbólico con una larguísima historia las piezas concretas de su propia parcela de la cultura de masas contemporánea y el conflicto que se libraba en esos momentos.

\subsection{Condiciones de recepción: una nación dispuesta a aniquilar a otra}

Es bien sabido que lo que precipitó la entrada de Estados Unidos en la II Guerra Mundial fue el bombardeo sobre sus instalaciones militares en Pearl Harbor. Si bien existían numerosos sectores en el país norteamericano que solicitaban a su gobierno el fin del aislacionismo para ayudar a poner fin al avance del fascismo en Europa, tal paso sólo se dio como corolario de la respuesta a la agresión por parte de los aliados japoneses del Eje en el escenario del Pacífico. El día después del ataque a la base hawaiana, el presidente Franklin Delano Roosevelt abría su comparecencia en el capitolio ante los miembros del senado y el congreso con las inmortales palabras: "Yesterday, December 7th, 1941 - a date which will live in infamy - the United States of America was suddenly and deliberately attacked by naval and air forces of the Empire of Japan". Después de destacar la especial ruindad del acto por no haber mediado una declaración de guerra y tras repasar los otros objetivos golpeados por la nación asiática en las últimas horas, Roosevelt se arrogaba la voz de todos los ciudadanos bajo su gobierno al prometer:

But always will our whole nation remember the character of the onslaught against us. No matter how long it may take us to overcome this premeditated invasion, the American people in their righteous might will win through to absolute victory. [...] we will not only defend ourselves to the uttermost but will make it very certain that this form of treachery shall never again endanger us. Hostilities exist. There is no blinking at the fact that our people, our territory and our interests are in grave danger. With confidence in our armed forces-with the unbounding determination of our people-we will gain the inevitable triumph-so help us God ${ }^{20}$.

De este modo, la empresa bélica de alcance global que se extendería durante los cuatro años siguientes quedaba formulada en términos de defensa y venganza, en virtud de un destino

20 Transcripción del discurso en "The President's Message", en New York Times (9 de dieciembre de 1941), p. 1. 
manifiesto y con el apoyo divino, contra una agresión atroz llevada a cabo sin aviso ni provocación. Apenas un par de meses después de su inicio, Roosevelt emitió la Orden Ejecutiva no $9066^{21}$, por la cual se instaba a las autoridades militares a recluir en campos de internamiento a todo aquél de ascendencia japonesa que permaneciera en la costa del Pacífico de los Estados Unidos. No hubo, sin embargo, un equivalente en alcance o magnitud aplicado a residentes o ciudadanos de ascendencia italiana o alemana, en cuyos casos las reclusiones fueron más escasas, más dispersas y de menor duración. Por si cupiera alguna duda de las motivaciones racistas que animaron tan desigual aplicación de esta normativa de seguridad, bastan para despejarla las palabras del Teniente General John L. DeWitt, responsable del Ilamado Programa de Evacuación y Detención: "a Jap is a Jap" (en Koppes y Black, 1990: 250). Era evidente el eco del lema "Good Indians... Dead Indians", con lo que se reactivaba para el enemigo japonés todo el aparato simbólico elaborado siglos atrás contra el nativo nortemamericano:

Such wilfully planned and ruthlessly executed destruction of the Native Americans needed its battle slogan, a ready-made catch phrase that could help the perpetrators to justify the inhuman treatment of their victims [...] Its multisemanticity is grotesque to say the least. [...] $\mathrm{Be}$ it physical or spiritual death, Native Americans were doomed victims of perpetrators who acted with manifest destiny on their side while so-called innocent by-standers did nothing to prevent the holocaust of Native Americans (Mieder, 1997: 142).

Americans fit the savage war in the Pacific into one of the oldest archetypes of their popular culture -Indian warfare [...] Japanese tactics -treachery, camouflage, deception- recalled the perceived barbarity of Indian methods (en Koppes y Black, 1990: 253)

En tales circunstancias, no es de extrañar que, pese a su dudosa constitucionalidad, el Tribunal Supremo revalidara la reclusión masiva de japoneses-estadounidenses a finales de $1944^{22}$. Por las mismas fechas, el American Institute of Public Opinión del Dr. George Gallup publicó los resultados de una encuesta cuya pregunta básica era: "What do you think we should do with Japan as a country after the war?". La opción mayoritaria (33\%) era que "Japan should be split up or destroyed as a political entity", mientras que una minoría significativa (13\%) era partidaria de una solución aún más radical: "'killing off' all the Japanese", tanto militares como civiles, cualquiera que fuese su edad, sexo o condición ${ }^{23}$. La respuesta era acorde con la percepción que había detectado el corresponsal de guerra Ernie Pyle: "the Japanese were looked upon as something subhuman or repulsive; the way some people feel about cockroaches or mice" (en Koppes y Black, 1990: 253). En palabras de otro cronista, los estadounidenses consideraban a los japoneses una "nameless mass of vermin",

\footnotetext{
${ }^{21}$ El texto de esta orden, fechada el 19 de febrero de 1942, puede leerse, por ejemplo, en: http://www.ourdocuments.gov/doc.php?flash=false\&doc=74\&page=transcript (consultada el 7 de junio de 2010).

${ }^{22}$ Como resolución del caso Toyosaburo Korematsu v. United States, 323 U.S. 214 (1944), cerrado el 18 de diciembre de 1944 y a cuyo texto puede accederse en: http://caselaw.Ip.findlaw.com/scripts/getcase.pl?court=US\&vol=323\&invol=214 (consultado el 7 de junio de 2010).

23 Posturas más moderadas apostaban por: "supervision and control" (28\%) y "reeducation" ( $8 \%$ ). Estos datos fueron publicados originalmente en un comunicado de prensa del Public Opinion News Service (Princeton, 19 de diciembre de 1944) y para la elaboración del presente artículo se ha accedido a ellos a través de "Public Opinion Polls on Japan", en Far Eastern Survey, vol. 19, no 10 (17 de mayo de 1950 ), pp. 101-103
} 
lo que sin duda reforzaba la representación propagandística de "war as pest control" (Russell, 2001: 98-99).

Durante los meses que restaban de guerra, Estados Unidos sometió a Japón a un castigo sin precedentes desde el cielo. El poder de las fuerzas aéreas estadounidenses, especialmente las nuevas superfortalezas aéreas B-29, se aplicó en arrojar una auténtica lluvia de fuego sobre la nación imperial. Esta campaña culminó en el bombardeo de Tokyo en marzo de 1945, sobre el cual informó el U.S. Strategic Bombing Survey que "probably more persons lost their lives by fire at Tokyo in a 6-hour period than at any [equivalent period of] time in the history of man" (en Rhodes, 1986: 734). La naturaleza extraordinaria de las bombas arrojadas más tarde sobre Hiroshima y Nagasaki ha eclipsado en la memoria histórica los episodios de destrucción de los meses anteriores. En términos absolutos, el bombardeo convencional masivo sobre la capital había provocado mayor aniquilación, pero lo que habían conseguido tan sólo dos artefactos con sus respectivos corazones de uranio y plutonio marcaba el inicio de una nueva era. Así lo manifestaba el presidente Truman, tras la destrucción de Hiroshima, recogiendo además el espíritu de las palabras que pronunciara su difunto antecesor al declarar la guerra:

\begin{abstract}
The Japanese began the war from the air at Pearl Harbor. They have been repaid manifold. And the end is not yet. With this bomb we have now added a new and revolutionary increase in destruction to supplement the growing power of our armed forces. [...] It is an atomic bomb. It is a harnessing of the basic power of the universe. The force from which the sun draws its power has been loosed against those who brought war to the Far East. [...] What has been done is the greatest achievement of organized science in history [...] If they do not now accept our terms they may expect a rain of ruin from the air, the like of which has never been seen on this earth (Truman, 1945: 163-164).
\end{abstract}

Al igual que con la Antorcha Humana en los comic books, la ciencia estadounidense había sido capaz de someter a las fuerzas de la naturaleza para dirigirlas contra los enemigos de la nación. Truman cumplió su amenaza, pues no sólo dio orden de arrojar una segunda bomba atómica poco después sino que el país enemigo continuó siendo bombardeado por medios convencionales durante los pocos días que transcurrieron hasta su rendición. Aunque el presidente declaró por aquellas fechas que se habían escogido como objetivos Hiroshima y Nagasaki por tratarse de ciudades militares, sabía de antemano que, como en los demás ataques contra poblaciones japonesas, muchas víctimas serían civiles. Es más, según estas fuentes, en realidad las dos ciudades elegidas no habían sido bombardeadas aún porque tenían relativamente poco peso en el aparato militar japonés. En cambio, sí reunían una serie de condiciones que, a juicio de la inteligencia estadounidense, las hacía idóneas como campos de prueba de los ingenios atómicos, incluyendo el hecho de que su destrucción permitiría: "(1) obtaining the greatest psychological effect against Japan and (2) making the initial use sufficiently spectacular for the importance of the weapon to be internationally recognized when publicity on it is released" (Alperovitz, 1995: 521-524).

Meses después de que acabara la guerra, una encuesta de la revista Fortune mostraba que no sólo eran muy pocos (5\%) los ciudadanos estadounidenses que tenían una opinión 
negativa de los bombardeos atómicos sobre Hiroshima y Nagasaki, sino que un grupo mucho más numeroso (22.7\%) lamentaba que no se hubieran utilizado más bombas atómicas contra Japón ${ }^{24}$. Truman, por su parte, expresaría durante el resto de su vida su convicción de haber obrado correctamente y que la decisión de lanzar las bombas jamás le quitó el sueño: "I lost plenty of sleep, but not over saving Japanese lives. I lost sleep worrying about our boys [...] and it broke my heart when just one of our soldiers, sailors or marines died" (en Lifton y Mitchell, 1995: 176). Como indican los resultados de la encuesta y las palabras de Truman en particular, se había alcanzado tal estado de extrañamiento de los estadounidenses respecto a los japoneses que sus muertes, ni tan siquiera contadas por centenares de millares, provocaban alguna compasión. Al analizar cómo se había llegado a semejante situación, que carecía de equivalente por parte de los aliados en el teatro europeo de la II Guerra Mundial, Dower aislaba el racismo profundamente arraigado como elemento clave del proceso:

[...] in its most extreme form racism sanctions extermination -the genocide of the Jews, of course, but also the plain but patterned rhetoric of exterminating beasts, vermin, or demons that unquestionably helped raise tolerance for slaughter in Asia [...] The psychology of the hunt became indistinguishable from a broader psychology of extermination that came to mean not merely taking no prisoners on the battlefield, but also having no qualm about extending the kill to the civilian population in Japan. Here the more precise language and imagery of the race war became apparent. The Japanese were vermin [...] These were classic tropes of racist denigration, deeply embedded in European and American consciousness. War simply pried them loose [...] incinerating Japanese in caves with flamethrowers was referred to as 'clearing out a rats' nest.' Soon after Pearl Harbor, the prospect of exterminating the Japanese vermin in their nest at home was widely applauded (1996: 173-175).

La guerra activó actitudes y prejuicios de diversa índole que ya estaban presentes, de manera más o menos soterrada, en la cultura estadounidense para dotar de contenidos a los mecanismos, tal vez universales, de la propaganda bélica. Varios de los principios de ésta pueden leerse sin dificultad en el mito de la II Guerra Mundial construido por y para los vencedores estadounidenses: nosotros no queremos la guerra; el adversario es el único responsable de la guerra; el enemigo tiene el rostro del demonio; los fines reales de la guerra son enmascarados como nobles causas; nuestras pérdidas son pequeñas, mientras que las del enemigo son enormes; nuestra causa tiene un carácter sagrado; etc25. Todos ellos están presentes en el discurso propagandístico contra Japón que se elaboró durante los años de la II Guerra Mundial, desde las arengas presidenciales que abrieron y cerraron las hostilidades hasta los mensajes vehiculados por las diversas manifestaciones culturales del periodo.

24 "The Fortune Poll", en Fortune, no 32 (diciembre de 1945), p. 305.

25 Tomados de Principios elementales de la propaganda de guerra, donde Anne Morelli sintetiza y actualiza en ejemplos posteriores las enseñanzas de la obra seminal de Arthur Ponsonby, Falsehood in Wartime (1928). 


\section{Conclusiones}

En las páginas anteriores hemos tratado de exponer la verificación de los mecanismos de propaganda bélica en una de las formas más populares de la cultura de masas de la época, los comic books de superhéroes, a través del caso concreto de una ilustración de portada. Para ello nos hemos apoyado en el modelo estructural del mensaje propagandístico de Pineda, gracias al cual hemos podido realizar un análisis cuyos resultados principales en cuanto a la localización de propagados y propagandemas se reflejan en el esquema siguiente:

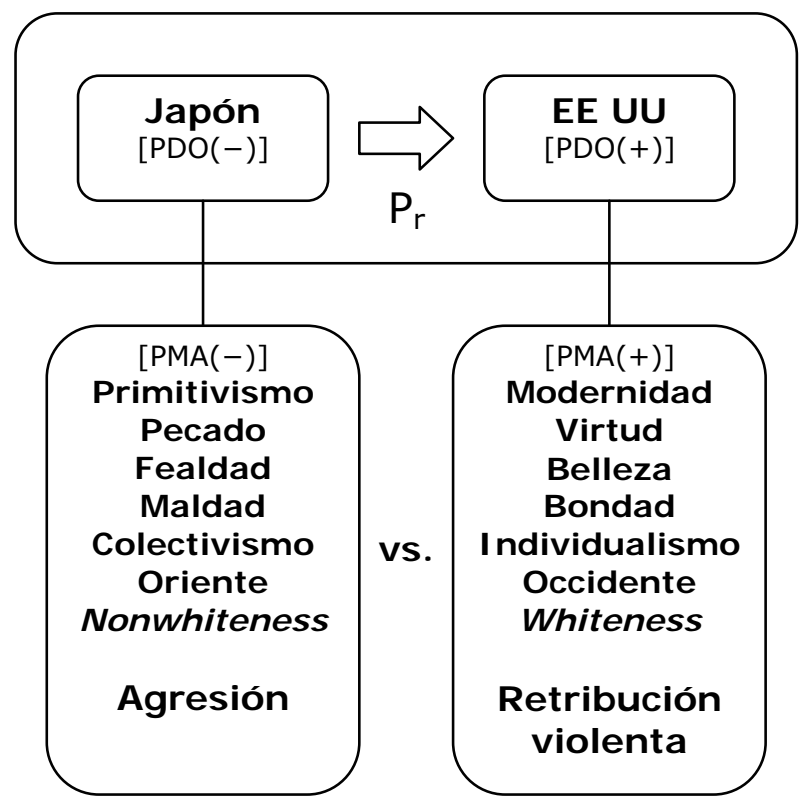

Como consecuencia de nuestra elección metodológica, una conclusión adicional del presente artículo es que el mencionado modelo describe adecuadamente el fenómeno comunicacional de la propaganda y funciona como una eficaz herramienta para el análisis de ejercicios concretos de dicho fenómeno. 


\section{Referencias bibliográficas}

ALPEROVITZ, Gar (1995): The Decision to Use the Atomic Bomb. New York, Vintage Books.

ARGAN, Giulio Carlo (1975): "Ideology and Iconology", en Critical Inquiry, vol. 2, núm. 2, pp. 297-305.

BARKIN, Steve M. (1984): "Fighting the Cartoon War: Information Strategies in World War II", en Journal of American Culture, no 7, pp. 113-117.

BARTHES, Roland (1964): "Rhétorique de I'image", en Communication, no 4, pp. 40-51.

CALVO SERRALLER, Francisco (2005): Los géneros de la pintura. Madrid, Taurus.

CAMPBELL, Joseph (2004): The Hero with a Thousand Faces, Commemorative Edition. Princeton, Princeton University Press.

CIRLOT, J.R. (2001): A Dictionary of Symbols. Londres, Routledge.

COOGAN, Peter (2006): Superhero: The Secret Origin of a Genre. Austin, MonkeyBrain Books.

COURTÉS, Joseph (1997): Análisis semiótico del discurso. Del enunciado a la enunciación. Madrid, Gredos.

DOWER, John (1986): War without Mercy: Race and Power in the Pacific War. Nueva York, Pantheon Books.

DOWER, John (1996): "Race, Language, and War in Two cultures: Wold War II in Asia", en Erenberg, L.A. y Hirsch, S.E., The War in American Culture: Society and Consciousness during World War II. Chicago y Londres, University of Chicago Press, pp.169-201.

DURAND, Jacques (1970): "Rhétorique et image publicitaire", en Communications, núm. 15, pp. 70-95.

ECO, Umberto (2003): "Narrative Structures in Fleming", en Lindner, C., The James Bond Phenomenon: A Critical Reader. Nueva York, Palgrave, pp. 34-55.

FALUDI, Susan (2007): The Terror Dream: Fear and Fantasy in Post-9/11 America. Nueva York, Metropolitan Books.

FERBER, Michael (2007): A Dictionary of Literary Symbols. Nueva York, Cambridge University Press.

FRYE, Northrop y MACPHERSON. Jay (2004): Biblical and Classical Myths: the Mythological Framework of Western Culture. Toronto, University of Toronto Press.

GROUPE $\mu$ (1993): Tratado del signo visual. Madrid, Cátedra.

GREIMAS, A. J. (1973): En torno al sentido. Ensayos semióticos. Madrid, Fragua. 
HAINING, Peter (2000): The Classic Era of American Pulp Magazines. Londres, Prion Books.

HALL, James (1996): Illustrated Dictionary of Symbols in Eastern and Western Art. Boulder, Westview Press.

HASENMUELLER, Christine (1978): "Panofsky, Iconography, and Semiotics", en The Journal of Aesthetics and Art Criticism, vol. 36, núm. 3, pp. 289-301.

JEWETT, R. y LAWRENCE, Shelton J. (1977): The American Monomyth. Nueva York, Doubleday.

JIMÉNEZ VAREA, Jesús (2004): "Historietas de superhéroes y propaganda bélica durante la II Guerra Mundial", en Huici Módenes, A. y Pineda Cachero, A., Propaganda y comunicación. Una aproximación plural. Sevilla, Comunicación Social, pp. 153-173.

JONES, Robert K. (1978): The Shudder Pulps: A History of the Weird Menace Magazines of the 1930s. West Linn, FAX Collector's Editions.

KOPPES, Clayton R. y BLACK, Gregory D. (1990): Hollywood Goes to War: How Politics, Profit and Propaganda Shaped World War II. Berkeley, University of California Press.

LIFTON, Robert Jay y MITCHELL, Greg (1995): Hiroshima in America: Fifty Years of Denial. New York, Grosset/Putman.

LUCKHURST, Roger (2005): "Introduction", en Luckhurst, R., Late Victorian Gothic Tales. Oxford y Nueva York, Oxford University Press, pp. ix-xxxi.

MCCLINTOCK, Anne (1995): Imperial Leather: Race, Gender, and Sexuality in the Colonial Contest. Nueva York, Routledge.

MIEDER, Wolfgang (1997): The Politics of Proverbs: From Traditional Wisdom to Proverbial Stereotypes. Madison y Londres, University of Wisconsin Press.

MOLES, Abraham (1981): L'image, communication fonctionnelle. París, Casterman.

MORELLI, Anne (2002): Principios elementales de la propaganda de guerra. Hondarribia, Hiru.

MURRAY, Chris (2000): "Popaganda: Superhero Comics and Propaganda in World War Two", en Magnussen, A. y Christiansen, H.C., Comics \& Culture: Analytical and Theoretical Approaches to Comics. Copenhague, Museum Tusculanum Press, pp. 141-156.

NEVINS, Jess (2003): Heroes \& Monsters: The Unofficial Companion to The League of Extraordinary Gentlemen. Austin, MonkeyBrain.

OESTERREICHER-MOLLWO, Marianne (1983): Símbolos. Madrid, Ediciones Riduero.

PANOFSKY, Erwin (1987): El significado en las artes visuales. Madrid, Alianza Editorial. 
PINEDA CACHERO, Antonio (2006): Elementos para una teoría comunicacional de la propaganda. Sevilla, Alfar.

REYNOLDS, Joshua (1831): "Sir Joshua Reynolds's Discourses. Discourse IV.December 10, 1771", en Arnold's Magazine of the Fine Arts, vol. II, pp. 2433.

RHODES, Richard (1986): The Making of the Atomic Bomb. Nueva York, Simon \& Schuster.

RUPERT, G.G. (1941): The Yellow Peril, or The Orient vs. The Occident. Britton, Union Publishing Co.

RUSSELL, Edmond (2001): War and Nature: Fighting Humans and Insects with Chemicals from World War I to Silent Spring. Nueva York, Cambridge University Press.

RYAN, T. A. y SCHWARTZ, C.B. (1956): "Speed of Perception as a Function of Mode of Representation", en American Journal of Psychology, núm. 96, pp. 66-69.

SLOTKIN, Richard (1973): Regeneration through Violence: The Mythology of the American Frontier, 1600-1860. Middleton, Wesleyan University Press.

SMEDLEY, Audrey (1993): Race in North America: Origin and Evolution of a Worldview. San Francisco, Westview Press.

STRÖMBERG, Fredrik (2010): Comic Art Propaganda. A Graphic History. Lewes, Ilex Press.

SUNDELL, Abner (2000): "How to Crash the Comics!", en Alter Ego, vol. 3, no4, pp. 27-34.

TODISH, Timothy, TODISH, Terry y SPRING, Ted (1998): Alamo Sourcebook, 1836: A Comprehensive Guide to the Battle of the Alamo and the Texas Revolution. Austin, Eakin Press.

TRUMAN, Harry S. (1945): "The Report of President Truman on the Atomic Bomb", en Science, vol. 102, no 2642, pp. 163-165.

TSU, Ying (2005): Failure, Nationalism, and Literature. The Making of Modern Chinese Identity. Stanford, Stanford University Press.

[Recibido: 9 de octubre de 2010. Aceptado: 19 de octubre de 2010.] 